\title{
Technical Guidance for Society Preparedness to Encounter Earthquakes and Tsunami In Kanagarian Api-Api Pasar Baru, Kecamatan Bayang Pesisir Selatan
}

\author{
Syafriani* , Hamdi, Nidya Yulfriska \\ Jurusan Fisika, Fakultas Matematika dan Ilmu Pengetahuan Alam, Universitas Negeri Padang, Jl. Prof. Dr. Hamka Air \\ Tawar, Indonesia \\ *syafri@fmipa.unp.ac.id
}

Diterima 9 Desember 2019, Disetujui 14 Nopember 2020, Dipublikasikan 30 Nopember 2020

\begin{abstract}
Wilayah Kanagarian Api-Api Kecamatan Bayang, Kabupaten Pesisir Selatan secara geografis berada di wilayah pesisir pantai dan tektonik aktif yang menyebabkan gempabumi. Gempabumi yang terjadi di lautan bisa menyebabkan terjadinya Tsunami. Oleh karena itu sangat penting untuk memberikan pengetahuan kepada masyarakat yang tinggal di daerah yang rawan terhadap bencana gempa bumi dan tsunami khususnya daerah yang dekat dengan Pantai tentang bahaya dari gempabumi dan tsunami. Kegiatan pengabdian kepada masyarakat ini dilakukan di 2 tempat yaitu di UPT SD.N 38 Api-Api dan di Kantor Wali Nagari Api-Api Kecamatan Bayang Kabupaten Pesisir Selatan. Pengetahuan yang diberikan ini bertujuan agar dapat membantu mengukur kesiapsiagaan masyarakat akan datangnya bencana. Sehingga masyarakat dapat lebih siap dan siaga dalam menghadapi bencana serta dapat meminimalisir dampak yang terjadi akibat bencana tersebut.
\end{abstract}

Keywords - Gempabumi, Tsunami, Kanagarian Api-Api, Bayang Pesisir Selatan

This is an open access article distributed under the Creative Commons 4.0 Attribution License, which permits unrestricted use, distribution, and reproduction in any medium, provided the original work is properly cited. (C)2017 by author and Universitas Negeri Padang.

\section{Pendahuluan}

Gempa bumi (earthquakes) dan Tsunami merupakan salah satu bencana alam terbesar bagi umat manusia. Gempa yang pernah terjadi di Sumatera Barat tepatnya di Kota Padang pada tanggal 30 September 2009 dan di Kepulauan Mentawai pada tahun 2010 yang diikuti dengan terjadinya tsunami, menjadi hal yang paling menakutkan bagi masyarakat yang tinggal di daerah Kota Padang, terutama di daerah yang dekat dengan Pantai. Salah satu daerah yang dekat dengan Pantai dan rawan terhadap bencana gempabumi dan tsunami yaitu daerah Kabupaten Pesisir Selatan.

Berdasarkan Peraturan Gempa Indonesia, Sumatera Barat merupakan salah satu provinsi yang memiliki percepatan gempabumi maksimum dan tertinggi di Indonesia (SNI-1726, 2002). Dimana dalam catatan sejarah, daerah pesisir Pantai Barat Sumatera sudah pernah terjadi 2 kali tsunami yaitu pada tahun 1797 dann $1833^{[1]}$. Dalam beberapa tahun kedepan para ahli juga meprediksi akan terjadi gempa besar megathrust yang merupakan siklus gempa pada subduksi Sumatera yang berada antara pulau Pagai Selatan dengan Pulau Batu di Kepulauan Mentawai. Gempa ini juga berpotensi menimbulkan tsunami yang akan menghantam pantai barat pulau Sumatera, terutama Sumatera Barat.

Hubungan Kesiapsiagaan antara tinggi tsunami dengan tipe prakiraan tsunami dijelaskan oleh CDIT (2009), yang ditunjukkan pada Gambar 1. 


\begin{tabular}{|l|l|c|}
\hline \multicolumn{1}{|c|}{$\begin{array}{c}\text { Tipe } \\
\text { prakiraan }\end{array}$} & \multicolumn{1}{|c|}{ Tipe pengumuman } & $\begin{array}{c}\text { Tinggi tsunami } \\
\text { dalam m }\end{array}$ \\
\hline $\begin{array}{l}\text { Waspada } \\
\text { tsunami }\end{array}$ & $\begin{array}{l}\text { Diperkirakan tsunami dengan ketinggian maksimum } \\
0,5 \mathrm{~m} \text {. Saran, berhati-hatilah }\end{array}$ & 0,5 \\
\hline Siaga tsunami & $\begin{array}{l}\text { Diperkirakan tsunami dengan ketinggian maksimum } \\
2 \mathrm{~m} \text {. Saran : sangat siaga }\end{array}$ & $1-2$ \\
\hline $\begin{array}{l}\text { Sangat siaga } \\
\text { tsunami }\end{array}$ & $\begin{array}{l}\text { Diperkirakan tsunami dengan ketinggian maksimum } \\
3 \mathrm{~m} \text { atau lebih. Saran : sangat siaga }\end{array}$ & $>3$ \\
\hline
\end{tabular}

Gambar 1 : Tinggi Tsunami dan Tipe Perkiraan

Secara umum, masyarakat yang berada di daerah Sumatera Barat terutama di Kanagarian Api-Api Kecamatan Bayang Kabupaten Pesisir Selatan masih rentan dan masih mempunyai pengetahuan yang kurang tentang bahaya dari bencana gempabumi dan tsunami. Sehingga sangat penting dilakukannya suatu upaya untuk meminimalisir dampak dari bencana gempabumi dan tsunami ini. Salah satunya upaya yang dapat dilakukan untuk meminimalisir dampak dari bencana gempabumi dan tsunami yaitu melakukan penelitian kesiapsiagaan masyarakat dalam mengantisipasi gempabumi dan tsunami serta memberikan bimbingan teknis kesiapsiagaan masyarakat untuk menghadapi bencana gempabumi dan tsunami. Kegiatan Pengabdian Kepada Masyarakat ini sebelumnya juga sudah pernah dilakukan di daerah Pasar Baru Kecamatan Bayang Pesisir Selatan ${ }^{[4]}$.

\section{Metode Penelitian}

Kegiatan Pengabdian Kepada Masyarakat yang berjudul Bimbingan Teknis Kesiapsiagaan Masyarakat untuk menghadapi Gempabumi dan Tsunami ini dilakukan di dua daerah yaitu di UPT SD.N 38 Api-Api Kecamatan Bayang, Pesisir Selatan dan di Kantor Wali Nagari Api-Api Pasar Baru, Kecamatan Bayang, Pesisir Selatan. Daerah ini merupakan daerah yang sangat rawan terhadap bencana gempabumi dan tsunami. Hal ini disebabkan karena kedua daerah ini merupakan daerah yang terletak sangat dekat dengan Pantai yaitu Pantai Pesisir Selatan. Kegiatan bimibingan teknis kesiapsiagaan masyarakat untuk mengahadapi bencana gempabumi dan tsunami ini bertujuan untuk membantu masyarakat yang berada di daerah rawan bencana tersebut untuk dapat lebih siapsiaga dalam menghadapi jika terjadinya bencana gempabumi dan tsunami.

Dalam kegiatan ini diberikan secara langsung bimbingan teknis kepada murid-murid
UPT SD.N 38 Api-Api Kecamatan Bayang, Pesisir Selatan beserta Guru-gurunya dan kepada masyarakat yang berada di Kanagarian Api-Api Pasar Baru, Kecamatan Bayang, Pesisir Selatan. Bimbingan teknis yang diberikan dalam kegiatan ini berupa presentasi dan diskusi dengan Murid, Guru beserta Masyarakat tentang hasil-hasil penelitian terakhir mengenai bencana Gempabumi dan Tsunami, sifat-sifat Fisika yang berkaitan dengan Gempabumi dan Tsunami, parameter-parameter Gempabumi dan Tsunami serta cara mitigasi atau upaya penyelamatan diri agar menimimalisir dampak dari bahaya bencana Gempabumi dan Tsunami.

Kegiatan selanjutnya yang dilakukan setelah presentasi dan diskusi mengenai hal di atas yaitu mengukur kesiapsiagaan masyarakat akan datangnya bencana gempabumi dan tsunami. Hal ini dilakukan denga cara wawancara secara langusung kepada murid-murid UPT SD.N 38 Api-Api Kecamatan Bayang, Pesisir Selatan. Wawancara ini bertujuan untuk melihat pengetahuan murid-murid setelah diberikannya bimbingan teknis kesiapsiagaan untuk menghadapi bencana gempabumi dan tsunami. Sedangkan untuk masyarakat yang berada di Wali Nagari Api-Api Pasar Baru, Kecamatan Bayang, Pesisir Selatan dilakukan pengukuran kesiapsiagaan dengan cara memberikan kuisioner kepada masyarakat untuk melihat kesiapsiagaan masyarakat dalam menghadapi bencana gempabumi dan tsunami. Kuisioner yang diberikan berisi tentang 4 Materi, yaitu Pengetahuan tentang Bencana (KAP), Rencana Kesiapsiagaan Keluarga dari Bencana (EP), Peringatan Bencana (WS) dan Mobilisasi Sumber Daya (RMC). Dengan dilkakukannya kegiatan Bimbingan Teknis kesiapsiagaan masyarakat untuk menghadapi bencana gempabumi dan tsunami ini diharapkan gar masyarakat mempunyai pengetahuan dan lebih siapsiaga dalam menghadapi jika terjadinya bencana gempabumi dan tsunami di daerah tersebut.

\section{Hasil dan Pembahasan}

Berdasarkan kegiatan bimbingan teknis kesiapsiagaan masyarakat untuk menghadapi gempabumi dan tsunami yang telah dilakukan di Kanagarian Api-Api Kecamatan Bayang, Pesisir 
Selatan pada 2 tempat yaitu tepatnya di UPT SD.N 38 Api-Api Kecamatan Bayang Pesisir Selatan dan di Kantor Wali Nagari Api-Api Kecamatan Bayang Pesisir Selatan. Masyarakat yang berada di wilayah ini mendapatkan pengetahuan tentang apa itu bencana gemabumi dan tsunami, cirri-ciri gempabumi dan tsunami, paramter-parameter gempabumi dan tsunami, sifat-sifat fisika yang berkaitan dengan gempabumi dan tsunami serta upaya mitigasi untuk meminimalisir dampak dari bencana gempabumi dan tsunami. Sehingga setelah dilakukannya kegiatan ini, diharapkan masyarakat yang berada di daerah ini menjadi lebih waspada, siap dan siaga dalam menghadapi bencana gempabumi dan tsunami, karena daerah ini merupakan daerah yang rawan terhadap bencana gempabumi dan tsunami.

Untuk mengukur kesiapsiagaan masyarakat dalam menghadapi bencana gempabumi dan tsunami, dilakukan dengan dua cara yaitu dengan cara wawancara langsung kepada murid-murid di UPT SD.N 38 Api-Api Kecamatan Bayang, Pesisir Selatan dan dengan memberikan kuisioner kepada masyarakat yang berada di Wilayah Kanagarian Api-Api Kecamatan Bayang, Kabupaten Pesisir Selatan.

Berdasarkan hasil wawancara pada muridmurid yang berada di UPT SD.N 38 Api-Api Kecamatan Bayang, Pesisir Selatan dapat diketahui bahwa setelah diadakannya kegiatan bimbingan teknis kesiapsiagaan masyarakat untuk menghadapi gempabumi dan tsunami di Kanagarian Api-Api Kecamatan Bayang Pesisir Selatan ini terutama di UPT SD.N 38 Api-Api, murid-murid menjadi tahu apa itu bencana, cirriciri dari gempabumi dan tsunami, dampak dari gempabumi dan tsunami serta bagaimana cara untuk menyelamatkan diri jika terjadi bencana gempabumi dan tsunami tersebut. Dimana sebelum diberikannya bimbingan teknis ini, murid-murid yang berada di UPT SD.N 38 ApiApi Kecamatan Bayang, Pesisir Selatan masih mempunyai pegetahuan yang sedikit tentang bencana dan cara menyelamatkan diri jika terjadinya bencana gempabumi dan tsunami. Jadi kegiatan yang dilakukannya ini sangat penting dan memberikan manfaat yang besar terutama bagi murid-murid di UPT SD.N 38 Api-Api Kecamatan Bayang, Pesisir Selatan.

Sedangkan untuk mengukur kesiapsiagaan masyarakat yang berada di Wali Nagari Api-Api, diberikan kuisioner yang terdiri dari beberapa materi. Materi I yaitu tentang Pengetahuan Masyarakat tentang Bencana yang terdiri dari 11 Pertanyaan. Data Hasil Pengetahuan Masyarakat tentang Bencana (KAP) ditunjukkan dalam Gambar 2.

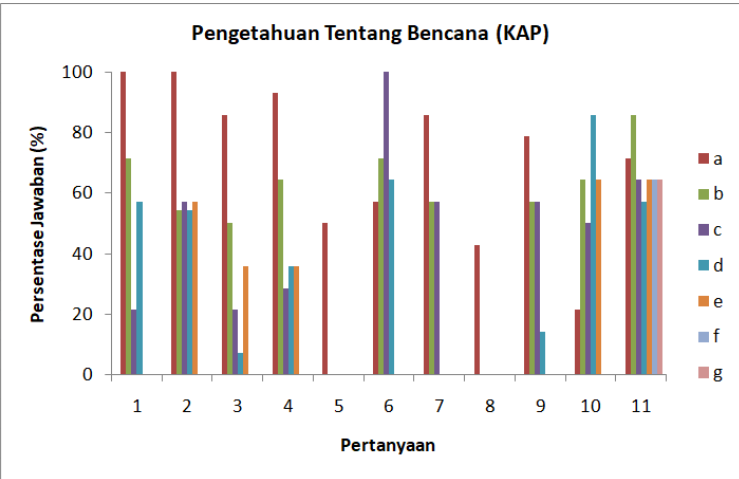

Gambar 2. Grafik Data Pengetahuan

Masyarakat tentang Bencana (KAP).

Gambar 2 di atas memperlihatkan hasil evaluasi pengetahuan masyarakat tentang Bencana (KAP). Pada pengetahuan yang pertama yaitu tentang pengertian dari bencana alam, , dimana jawaban (a) menunjukan bahwa bencana alam merupakan kejadian alam yang mengganggu kehidupan manusia, jawaban (b) yaitu perilaku manusia yang menyebabkan kerusakan alam, jabawan (c) yaitu bencana akibat kerusuhan sosial/ politik dan jawaban (d) merupakan bencana akibat kebakaran hutan/serangan hama. Berdasarkan hasil evaluasi menunjukan bahwa rata-rata masyarakat menjawab dengan jawaban paling banyak adalah "a" yaitu kejadian alam yang mengganggu kehidupan manusia, dengan persentase jawaban (a) sebesar $100 \%$. Hal ini menunjukkan bahwa masyarakat telah memahami bahwa bencana alam merupakan suatu kejadian alam yang dapat mengganggu kehidupan manusia.

Pertanyaan selanjutnya yaitu tentang kejadian alam apa saja yang dapat menimbulkan bencana. Berdasarkan hasil evaluasi di atas dapat diketahui bahwa rata-rata masyarakat telah mengetahui kejadian alam apa saja yang dapat menimbulkan bencana, yaitu seperti Gempabumi 
(a), Tsunami (b), Tanah Longsor (c), Letusan Gunung Berapi (d) dan Badai (e). Kemudian pada pertanyaan ketiga yaitu tentang apa saja penyebab terjadinya gempa. Jawaban rata-rata dari masyarakat Kanagarian Api-Api Kecamatan Bayang Pesisir Selatan yaitu gempa bumi disebabkan oleh Pergeseran Kerak Bumi (a) dan Gunung Meletus (b) dengan persentase sebesar $85,7 \%$ dan $50 \%$.

Pertanyaan selanjutnya yaitu bencana alam apa saja yang dapat diakibatkan oleh gempa (pertanyaan ke 4). Dari hasil jawaban masyarakat, rata-rata masyarakat menjawab bencana alam yang dapat diakibatkan oleh gempa yaitu bencana Tsunami, ini ditunjukkan dengan hasil kuisioner yang mempunyai persentase jawaban "a" terbesar yaitu sebesar 92,9\%. Namun pada pertanyaan kelima yaitu apakah gempa bumi dapat diperkirakan kapan terjadinya, sebagian masyarakat masih ada yang menjawab ya (a).

Selanjutnya pada pertanyaan keenam yaitu apa saja ciri-ciri dari gempa kuat, dapat dilihat bahwa rata-rata masyarakat telah mengetahui apa saja ciri-ciri dari gempa kuat seperti (a) gempa membuat pusing/limbung, (b) gempa menyebabkan goyangan yang kencang/keras sehingga orang tidak bisa berdiri, (c) getaran gempa terjadi cukup lama dan diikuti oleh gempa-gempa susulan yang lebih kecil dan (d) bangunan retak atau roboh. Kemudian pada pertanyaan apa saja yang akan dilakukan apabila terjadi gempa, rata-rata masyarakat Kanagarian Api-Api telah mengetahui apa saja yang harus dilakukan jika terjadi gempa. Ini terlihat dari jawaban masyarakat pada kuisioner tersebut. Dimana hal yang harus dilakukan jika terjadi gempa yaitu (a) berlindung di tempat aman (misal bawah meja yang kokoh), (b) melindungi kepala dan (c) langsung berlari menuju dataran tinggi/bukit.

Pada pertanyaan ke delapan yaitu apakah setiap gempa bumi dapat menyebabkan tsunami, menunjukkan bahwa sebagian dari masyarakat masih ada yang belum memahami bahwa tidak semua gempa bumi dapat menyebabkan tsunami. Hal ini terlihat dari jawaban masyarakat pada pertanyaan kedelapan tersebut. Selanjutnya tentang kejadian yang bisa menyebabkan tsunami, rata-rata masyarakat menjawab dengan jawaban "a" yaitu gempa bumi di bawah laut dengan persentase jawaban rata-rata sebesar 78,6 $\%$.

Pertanyaan ke sepuluh tentang tandatanda/gejala tsunami yang diketahui, rata-rata masyarakat sudah mengetahui apa saja tandatanda/gejala dari tsunami. Ini ditandai dengan jawaban masyarakat pada kuisioner yang diberikan. Dimana jawaban (a) yaitu gempa lemah yang dirasakan seperti mengayun tapi cukup lama, lebih dari 2 menit, jawaban (b) gempa menyebabkan goyangan yang kencang/keras sehingga orang tidak bisa berdiri, jawaban (c) gelombang besar di cakrawala, jawaban (d) bunyi yang keras seperti ledakan dan/atau bunyi gemuruh seperti pesawat terbang dan jawaban (e) air laut tiba-tiba surut.

Pengetahuan tentang bencana (KAP) yang terakhir yaitu darimana masyarakat mendapatkan informasi tentang gempa dan tsunami, rata-rata sebagian besar masyarakat menjawab bahwa mereka mendapatkan informasi dari televisi (TV), ini ditunjukkan dari hasil kuisioner yang menunjukkan jawaban (b) sebesar 85,7 \%.

Hasil kuisioner tentang materi Rencana Kesiapsiagaan Keluarga dari Bencana (EP) ditunjukkan pada Gambar 3.

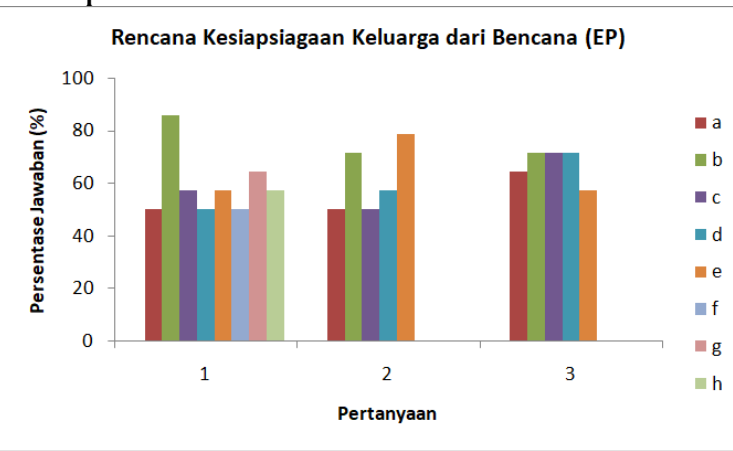

Gambar 3. Grafik Data Rencana

Kesiapsiagaan Keluarga dari Bencana (EP).

Gambar 3 menunjukkan data hasil Rencana Kesiapsiagaan Keluarga dari Bencana (EP). Berdasarkan Grafik di atas dapat dilihat bahwa setelah diadakannya kegiatan bimbingan teknis kesiapsiagaan masyarakat untuk menghadapi bencana gempabumi dan tsunami di Kanagarian Api-Api Pasar Baru Kecamatan Bayang Pesisir Selatan, masyarakat menjadi mengetahui apa saja rencana (pertanyaan 1) yang 
harus dibuat untuk menghadapi bencana gempabumi dan tsunami, tindakan apa saja yang harus dilakukan oleh anggota keluarga untuk menyelamatkan diri dari bencana gempabumi dan tsunami (pertanyaan 2) serta dimana saja tempat menyelamatkan diri masing-masing keluarga apabila terjadi gempabumi dan tsunami (pertanyaan 3). Dimana masing-masing keluarga telah menyiapkan rencana pada pertanyaan pertama seperti menyiapkan tindakan yang harus dilakukan masing-masing anggota keluarga (a), menyepakati tempat pengungsian/evakuasi (b), menyiapkan peta dan rute pengungsian (c), menyiapkan makanan siap santap yang tahan lama seperlunya (d), menyiapkan kotak pertolongan pertama (e), menyiapkan pakaian, uang tunai dan kebutuhan khusus/darurat keluarga (f), menyiapkan dokumen-dokumen penting dan bernilai (g) dan mengikuti latihan/simulasi evakuasi (h).

Begitu juga dengan tindakan yang harus dilakukan untuk menyelamatkan diri dar bencanadan tsunami serta tempat-tempat untuk menyelamatkan diri apabila terjadi bencana gempabumi dan tsunami. Terlihat bahwa masyarakat sudah memahami dan mengetahui tindakan apa saja yang harus mereka lakukan untuk menyelamatkan diri dan kemana tempat untuk menyelamatkan diri apabila terjadi bencana gempabumi dan tsunami. Dimana tindakan yang dilakukan oleh keluarga untuk menyelamatkan diri dari bencana gempa dan tsunami meliputi (a) Menambah Pengetahuan tentang gempa dan tsunami (b) membuat rencana pengungsian/evakuasi (c) melakukan latihan simulasi evakuasi keluarga dan (e) pindah rumah dari pantai ke daratan yang lebih tinggi.

Pada bagian pertanyaan ketiga pada Rencana kesiapsiagaan keluarga dari bencana yaitu dimana saja tempat menyelamatkan diri masing-masing keluarga apabila terjadi bencana gempa bumi dan tsunami, terlihat rata-rata jawaban dari masyarakat yaitu (a) Rumah saudara/famili/kerabat/teman dekat yang aman sebesar $64,3 \%$, (b) tenda/posko bencana yang yang disediakan sebesar 71,4\%, (c) gedung/bangunan terdekat yang aman sebesar $71,4 \%$ (d) lapangan terbuka yang aman sebesar
$71,4 \%$ dan (e) tempat ibadah di dekat pantai sebesar $57,1 \%$.

Materi ketiga yaitu Peringatan Bencana (WS). Data hasil kuisioner tentang Peringatan Bencana (WS) diperlihatkan dalam Gambar 4.

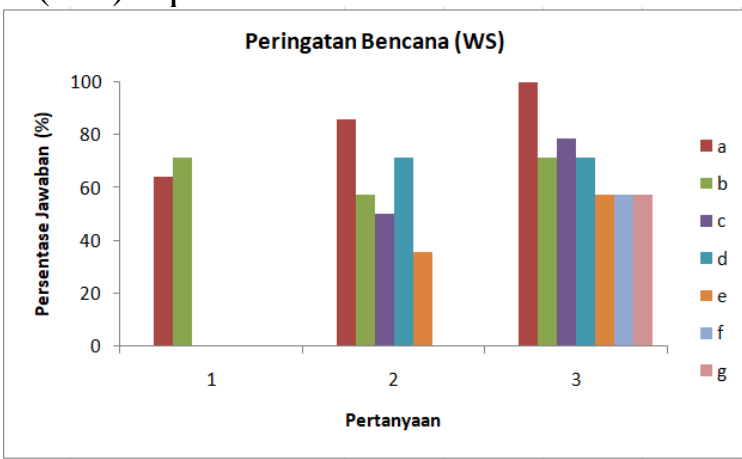

Gambar 4. Data Grafik Pengetahuan Masyarakat tentang Peringatan Bencana (WS).

Pada materi ketiga tentang Peringatan Bencana (WS) ini, terdapat 3 pertanyaan pada kuisionernya. Pertama yaitu pengetahuan masyarakat tentang tanda/cara peringatan tsunami di daerah Kanagarian Api-Api Kecamatan Bayang Pesisir Selatan. Rata-rata masyarakat menjawab dengan cara tradisional/kesepakatan lokal (a) sebesar $64,3 \%$ dan dengan cara sistem peringatan tsunami nasional (b) sebesar $71,4 \%$. Sumber informasi masyarakat untuk mendapatkan peringatan tsunami yaitu terlihat pada grafik peringatan bencana (WS) pada bagian kedua yaitu (a) Pemerintah kota/kabupaten/desa, (b) polisi dan aparat keamanan, (c) RRI dan Radio Swasta, (d) TVRI dan TV Swasta dan (e) Media cetak seperti koran dan majalah. Selanjutnya , pada pertanyaan hal-hal apa saja yang harus dilakukan saat mendengar peringatan atau tanda bahaya tsunami, terlihat bahwa dengan telah dilakukannya kegiatan bimbingan teknis kesiapsiagaan masyarakat untuk menghadapi gempabumi dan tsunami ini, masyarakat sudah memahami dan mengerti apa yang harus dilakukan saat mendengat peringatan atau tanda bahaya tsunami tersebut. Hal ini terlihat dari jawaban masyarakat pada kuisioner kesiapsiagaan, dimana masyarakat menjawab $100 \%$ dengan jawaban (a) menjahui pantai dan lari ke tempat/gedung yang tinggi, jawaban (b) bergegas menuju tempat penyelamatan/pengungsian/evakuasi dengan jawaban sebesar 71,4\%, jawaban (c) membawa 
tas/kotak/kantong siaga bencana yang berisis 1 . Makanan, 2. Pakaian, 3. Obat-obatan, 4. Dokumen penting, 5. Senter/baterai sebesar 78,6\%, jawaban (d) membantu anak-anak, ibu hamil, orang tua dan orang cacat keluar rumah menuju ke tempat aman sementara sebesar $71,4 \%$, jawaban (e) mematikan listrik, kompor, tungu, gas di rumah sebesar $57,1 \%$, jawaban (f) mengunci pintu sebelum meninggalkan rumah sebesar 57,1\% dan jawaban (g) menenangkan diri/tidak panik sebesar 57,1\%. Hal ini menunjukkan bahwa hanya sebagian masyarakat yang mematikan listrik kompor, dll sebelum mereka menyelamatkan diri dan meninggalkan rumah saat mendengar peringatan atau tanda bahaya tsunami.

Selanjutnya Data materi kuisioner yang terakhir yaitu Mobilisasi Sumber Daya (RMC) dapat dilihat pada Gambar 5.

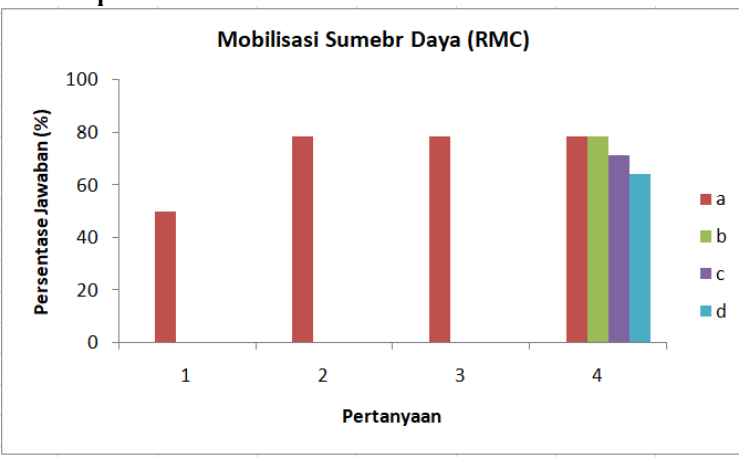

Gambar 5. Grafik Mobilisasi Sumber Daya (RMC).

Berdasarkan Grafik di atas dapat kita lihat bahwa pada bagian pertama pada grafik mobilisasi sumber daya yaitu tentang apakah gempa bumi dapat diperkirakan kapan waktu terjadinya, terlihat bahwa setengah dari masyarakat $(50 \%)$ sudah memahami bahwa bencana gempabumi tersebut tidak dapat diperkirakan kapan terjadinya. Namun masih ada juga masyarakat yang menjawab dapat diperkirakan. Selanjutnya pada bagian kedua yaitu tentang apakah rumah tangga/keluarga tersebut mempunyai aset/investasi yang dapat dimanfaatkan untuk kewaspadaan keluarga terhadap kemungkinan terjadinya bencana, ratarata masyarakat yang berada di Kanagarian ApiApi Kecamatan Bayang, Pesisir Selatan sudah mempunyai aset/investasi yang dapat dimanfaatkan untuk kewaspadaan jika terjadi bencana. Hal ini ditunjukkan pada Gambar 2 di atas, dimana masyarakat yang menjawab telah memiliki aset/investasi sebesar 78,6\%. Selain itu masyarakat di daerah tersebut juga mempunyai kerabat/teman yang siap membantu mereka jika terjadi bencana gempabumi dan tsunami. Ini terlihat dari jawaban hasil kuisioner pada point ke tiga yaitu dengan jawaban sebesar 78,6\%. Selanjutnya pada pertanyaan keempat yaitu mengenai hal yang sudah dipersiapkan untuk menghadapi kemungkinan terjadinya gempabumi dan tsunami, rata-rata masyarakat sudah mempersiapkan beberapa hal untuk menghadapi kemungkinan terjadinya gempabumi dan tsunami. Hal ini terlihat dari jawaban masyarakat pada hasil kuisioner. Dimana masyarakat yang menjawab dengan jawaban (a) membuat bangunan/rumah dari material yang ringan (misal kayu, bambu, seng) sebesar 78,6\%, dengan jawaban (b) membangun pondok sementara untuk mengungsi, di tempat aman/daerah bukit/tempat lebih tinggi dan jauh dari pantai sebesar 78,6\%, dengan jawaban (c) yaitu menyiapkan persediaan makanan dan pakaian secukupnya, tempat aman/daerah bukit/tempat lebih tinggi dan jauh dari pantai sebesar $71,4 \%$ dan dengan jabawan (d) yaitu menyiapkan persediaan cadangan (uang, modal, tanah) yang disimpan di tempat aman untuk menghadapi kemungkinan hilangnya pekerjaan akibat gempa dan tsunami sebesar $64,3 \%$.

Kesimpulan dari seluruh hasil data yang didapatkan dari kuisioner kesiapsiagaan masyarakat yang terdiri dari 4 materi dapat dilihat pada Gambar 6.

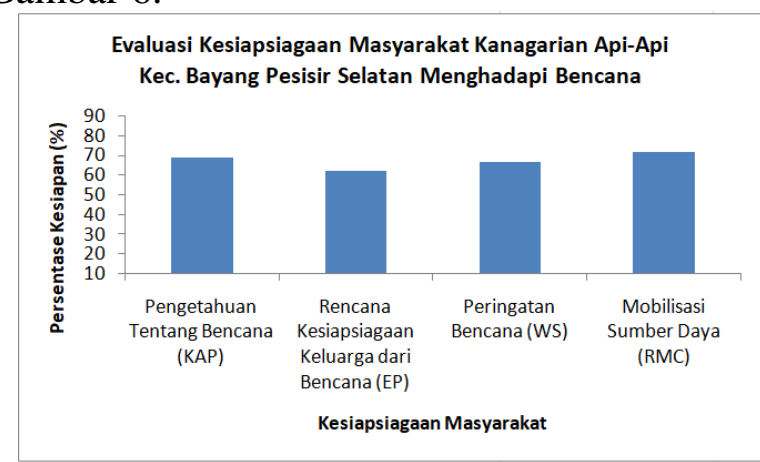

Gambar 6. Grafik Hasil Evaluasi

Kesiapsiagaan Masyarakat meghadapi Bencana.

Berdasarkan Grafik di atas dapat dilihat bahwa setalah diadakannya kegiatan Pengabdian 
Kepada Masyarakat yang berjudul "Bimbingan Teknis Kesiapsiagaan Masyarakat untuk Menghadapi Gempabumi dan Tsunami di Kanagarian Api-Api Kecamatan Bayang Pesisir Selatan, masyakarat telah mempunyai pengetahuan yang baik terhadap bencana (KAP) sebesar 68,7\%. Selanjutnya untuk Rencana Kesiapsiagaan Keluarga dari Bencana (EP) sebesar 62\%. Untuk Pengetahuan masyarakat tentang Sistem Peringatan Bencana (WS) masyarakat telah mempunyai pengetahuan sebesar 66,3 dan untuk Mobilisasi Sumber Daya (RMC) masyarakat pada Kanagarian Api-Api Kecamatan Bayang, Pesisir Selatan ini yaitu sebesar $71,4 \%$.

\section{Kesimpulan}

Berdasarkan hasil kegiatan Bimbingan Teknis Kesiapsiagaan Masyarakat untuk menghadapi Gempabumi dan Tsunami di Kanagarian Api-Api Pasar Baru, Kecamatan Bayang Pesisir Selatan yang telah dilakukan, dapat disimpulkan bahwa sebelum dilakukannya kegiatan bimbingan teknis ini, masyarakat masih mempunyai pengetahuan yang terbatas dalam kesiapsiagaan menghadapi bencana gempabumi dan tsunami. Namun setelah dilakukannya kegiatan bimbingan teknis ini, masyarakat yang berada di daerah Kanagarian Api-Api Pasar Baru Kecamatan Bayang, Pesisir Selatan terutama di UPT.SD.N 38 Api-Api dan Masyarakat Wali Nagari Api-Api Kecamatan Bayang Pesisir Selatan mempunyai pengetahuan yang lebih baik dalam kesiapsiagaan untuk mengahadapi bencana gempabumi dan tsunami tersebut. Sehingga masyarakt yang berada di derah ini dapat lebih waspada dan siaga serta dapat melakukan upaya penyelamatan diri untuk memnimalisir dampak dari bencana tersebut.

\section{Ucapan Terima Kasih}

Penulis mengucapkan terimakasih kepada Lembaga Penelitian dan Pengabdian Kepada Masyarakat UNP yang telah mendanai kegiatan ini melalu Skema Program Kemitraan Masyarakat Tahun Anggaran 2019 dengan Judul "Bimbingan Teknis Kesiapsiagaan Masyarakat di Kanagarian Api-Api Pasar Baru Kecamatan Bayang Pesisir Selatan.”, dengan nomor kontrak
1816/UN35.2/PM2019 tanggal 8 Juni 2019, Kepala Sekolah, Guru-guru besera murid-murid UPT SD.N 38 Api-Api Kecamatan Bayang Kabupaten Pesisir Selatan, Wali Nagari dan jajarannya serta Warga Nagari Api-Api Kecamatan Bayang Kabupaten Pesisir Selatan.

\section{Daftar Pustaka}

[1] Natawijaya, D.H., 2007, West Sumatera Tsunami Runup Modelling, Ristek.

[2] CDIT-Japan, 2009, Menyelamatkan diri dari Tsunami.

[3] Syafriani, S. 2018, An Investigation of Seismicity for the West Sumatra Region, Indonesia, IOP Conference Series: Material Science and Engineering, Vol 335, 25 April $2018 . \quad$ Doi: 10.1088/1757899X/335/1/012009.

[4] Syafriani, S., dkk. 2019, Education of Communities at The Earthquake and Tsunami Disaster in Kenagarian Pasar Baru Kecamatan Bayang Pesisir Selatan, Pelita Eksakta, Volume 2 Number 1, 2019, pp 6470. Doi: 10.24036/pelitaeksakta/vol2iss $1 / 41$. 